\title{
Caracterização de escória de ferro silício-manganês para uso em camadas de base e sub-base rodoviárias
}

O impacto gerado pelos resíduos da indústria siderúrgica provoca discussões acerca das melhores formas de destinação final dos subprodutos resultantes do processo de geração de ligas metálicas. Visando mitigar esses problemas, este trabalho apresenta os resultados dos estudos sobre a caracterização da escória de ferro silício-manganês para potencial aplicação em projetos de misturas com solo, na construção de camadas de base e sub-base de pavimento rodoviário. A relevância deste trabalho se mostra diante da necessidade de prover uma destinação ambientalmente adequada para subprodutos de processos siderúrgicos que podem prover a sociedade de soluções viáveis, ou seja, se tornar um coproduto que reduza o consumo de matéria-prima natural, além de promover economia financeira. Alguns métodos utilizados são tradicionais, como Granulometria, Densidade e absorção, e Abrasão Los Angeles. Outros são usados mais recentemente para caracterizar agregados, como Microscópio Eletrônico de varredura (MEV) e Sistema de caracterização de agregados por imagem (AIMS). Complementarmente, são apresentados os dados obtidos na Degradação após o teste de compactação Proctor e a determinação da perda ao choque no equipamento Treton. Os resultados encontrados nos ensaios mencionados se mostram satisfatórios diante dos valores estabelecidos nas normas específicas para cada metodologia. Finalmente, conclui-se que a escória de ferro de silício-manganês apresenta propriedades geotécnicas compatíveis com as estabelecidas para uso em base e subbase de pavimentos flexíveis.

Palavras-chave: Pavimento; Escória; Base; Sub-Base.

\section{Characterization of silicon-manganese iron slag for use in base and sub-base layers of highway}

\begin{abstract}
The impact generated by the waste from the steel industry leads to discussions about the best ways to dispose of by-products resulting from the metal alloy generation process. In order to mitigate these problems, this work presents the results of the studies on the characterization of silicon-manganese iron slag for potential application through soil-aggregate mixtures in the construction of base layers and sub-base of road pavement. The relevance of this work is shown by the need to provide an environmentally adequate destination for by-products of steelmaking processes that can provide the society with viable solutions, that is to become a co-product that reduces the consumption of natural feedstock, besides promoting economy financial management. Some methods used are traditional, such as Particle-size distribution, Density and absorption, and Los Angeles Abrasion. Others are used more recently to characterize aggregates, such as Scanning Electron Microscope (SEM) and Image Aggregation Characterization System (AIMS). In addition, the data obtained in the Degradation after the Proctor compaction test and the determination of the Shock loss in the Treton equipment are presented. The results found in the mentioned tests are satisfactory in front of the values established in the norms specific to each methodology. Finally, it is concluded that silicon-manganese iron slag has geotechnical properties compatible with those established for use in the base and sub-base of flexible pavements.
\end{abstract}

Keywords: Pavement Layers; Slag; Base; Subbase In Highway.

Topic: Sustentabilidade nos Transportes

Reviewed anonymously in the process of blind peer.

Filipe Batista Ribeiro (it)

Instituto Militar de Engenharia, Brasil

http://lattes.cnpq.br/6424323417858377

http://orcid.org/0000-0002-2077-6194

filipebatistaribeiro@gmail.com

Ben-Hur de Albuquerque e Silva (iD

Instituto Militar de Engenharia, Brasil

http://lattes.cnpq.br/6509325029666357

http://orcid.org/0000-0001-6933-498X

benhur@ime.eb.br

Álvaro Vieira

Instituto Militar de Engenharia, Brasil

http://lattes.cnpq.br/0394387879097680

alvaro@ime.eb.br

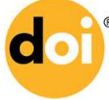

DOI: 10.6008/CBPC2179-6858.2018.002.0021
Received: $14 / 12 / 2017$

Approved: 24/01/2018
Referencing this:

RIBEIRO, F. B.; SILVA, B. A.; VIEIRA, A.. Caracterização de escória de ferro silício-manganês para uso em camadas de base e sub-base rodoviárias. Revista Ibero Americana de Ciências Ambientais, v.9, n.2, p.244-260, 2018. DOI: http://doi.org/10.6008/CBPC21796858.2018.002.0021 


\section{INTRODUÇÃO}

A construção de novas estradas geralmente implica numa interferência considerável no meio ambiente, relacionado tanto com o desmatamento para execução do eixo da via quanto com o aprovisionamento de grandes quantidades de agregados naturais necessários para a construção. Entretanto, devido ao aumento da conscientização ambiental no setor industrial, os construtores rodoviários têm concentrado os esforços na minimização de uso de recursos e no transporte de materiais, medidas demonstradas no uso de materiais reciclados (BIRGISDÓTTIR, 2005).

Tal senso de entendimento da finitude dos recursos naturais está amplamente descrito nas 8 Metas do Milênio da ONU, onde o primeiro tópico acerca da Qualidade de Vida e Respeito ao Meio Ambiente trata da integração dos princípios do desenvolvimento sustentável nas políticas e programas nacionais, assim como da reversão da perda de recursos ambientais. No decorrer dos anos, o investimento em soluções sobre a reciclagem de resíduos industriais vem sendo intensificada em muitos países. Diversas companhias vêm investindo em pesquisa e tecnologia para reutilização de rejeitos industriais, o que aumenta a qualidade do produto reciclado e propicia maior eficiência do sistema produtivo (TAKANO et al., 2000).

Nesse sentido, Arêdes (2016), em seu trabalho sobre a avaliação do comportamento mecânico das misturas asfálticas utilizando resíduo do beneficiamento do minério de ferro, propõe uma destinação final ambientalmente adequada para este resíduo arenoso, assim como, verifica a sua aplicabilidade como um material reaproveitável em pavimentação rodoviária, no intuito de reduzir o impacto ambiental negativo cada vez mais grave da estocagem deste resíduo.

A normatização tanto das características físicas e mecânicas do material, quanto da padronização da execução de sua aplicação são realizadas através de ensaios e análises técnicas. Conforme Nóbrega (2007), há pelo menos dois grandes grupos de escória: a de aciaria, proveniente da produção do aço obtida em fornos elétricos e conversores de oxigênio; e a de alto-forno, resultante da fusão redutora dos minérios para a obtenção do ferro gusa e ligas metálicas. Ainda nesse estudo, entende-se que uma das desvantagens de sua aplicação se encontra na grande variabilidade de sua geração, logo a utilização de uma metodologia que permita uma investigação prévia acerca das propriedades do material em questão se faz interessante para validar, ou não, o seu emprego nas pretendidas aplicações.

Segundo a ABNT NBR 7207/82 - Terminologia e classificação de pavimentos, o pavimento é uma estrutura construída após a terraplenagem e destinada economicamente e simultaneamente em seu conjunto a: resistir e distribuir ao subleito os esforços verticais produzidos pelo tráfego; melhorar as condições de rolamento quanto à comodidade e segurança; e resistir aos esforços horizontais que nele atuam tornando mais durável a superfície de rolamento. Este conceito está alinhado ao Manual de Pavimentação (MINISTÉRIO DOS TRANSPORTES, 2006), publicação IPR-719. Neste documento são apresentados os conceitos dos três tipos de pavimento, sendo eles o flexível, o semi-rígido e o rígido. O primeiro trata daquele em que todas as camadas sofrem deformação elástica significativa sob o carregamento aplicado e, portanto, a carga se distribui em parcelas aproximadamente equivalentes entre as camadas. O semi-rígido, caracteriza- 
se por uma base cimentada por algum aglutinante com propriedades cimentícias. Já o rígido, é aquele em que o revestimento tem uma elevada rigidez em relação às camadas inferiores, portanto, absorve praticamente todas as tensões provenientes do carregamento aplicado (MINISTÉRIO DOS TRANSPORTES, 2006).

Finalmente, este trabalho visa caracterizar a escória de ferro silício-manganês produzido em fornos elétricos, na região do quadrilátero ferrífero de Minas Gerais, para uso em camadas de pavimento flexível rodoviário. Isto através de parâmetros técnicos, obtidos através da realização de ensaios, definidos pelas normas vigentes dos órgãos competentes.

\section{METODOLOGIA}

Para avaliação do material, foram analisadas as principais normas brasileiras para validação do emprego em estruturas rodoviárias, tais como Análise granulométrica (DNER-ME 083/98), Determinação da absorção e da densidade aparente de agregado graúdo (DNER-ME 081/98) e Determinação da abrasão 'Los Angeles' (DNER-ME 035/98), cujos ensaios foram realizados no Laboratório de Solos do Instituto Militar de Engenharia (IME). Além disso, foram executados ensaios complementares, tais como composição mineralógica através de Espectroscopia de Energia Dispersiva (EDS) e imagens de Microscopia Eletrônica por Varredura (MEV), ambos realizados no Laboratório de Materiais do IME. Devido ao aspecto vítreo do material, foram realizados no Laboratório de Pavimentação do IME, ensaios de Índice de Degradação após compactação Proctor (DNER-ME 398/99) e Determinação de perda ao choque no aparelho Treton (DNER-ME 399/99).

\section{REVISÃO TEÓRICA}

Inicialmente, um dos principais tópicos a ser explicitado refere-se a algumas definições. Segundo a Lei 12.305/2010, resíduos sólidos são os materiais que ainda possuem algum valor para serem empregados, através de tecnologia disponível e de forma economicamente viável, mesmo que numa finalidade diferente daquela prevista inicialmente. Já os rejeitos, são caracterizados como os resíduos sólidos que, depois de esgotadas todas as possibilidades de tratamento e recuperação por processos tecnológicos disponíveis e economicamente viáveis, não apresentem outra possibilidade que não a disposição final ambientalmente adequada. Logo, utilizando a definição de Michaelis (2016), que trata a escória como resíduo sólido proveniente da fusão de metais ou da combustão de determinadas matérias, pode-se concluir que os elementos resultantes dos processos siderúrgicos, podem ora se apresentar como resíduo, e ora como rejeito. Finalmente, o material de estudo aqui a ser analisado, trata-se de uma escória, por ser resultante de processo onde ocorre o aquecimento de compostos metálicos e não metálicos até o ponto de fusão dos mesmos, e que vem sendo tratado como rejeito. Entretanto, alguns esforços vêm sendo empregados para torná-lo um resíduo reaproveitável com destinação final ambientalmente adequada.

Em consonância com o exposto acima, muitas empresas têm empregado esforços para tornar materiais que anteriormente eram vistos como subprodutos - materiais de valor que são produzidos como 
resíduo ou incidente do processo de produção - em coprodutos, ou seja, materiais caracterizados como mercadorias secundárias desejáveis que são geradas durante o processo de fabricação e podem ser vendidas ou reutilizadas de forma lucrativa (MARTINS, 2010). Acerca dos coprodutos da indústria, aqueles gerados pela siderurgia têm sido estudados largamente pelo maior produtor de aço do mundo, a China (MINISTÉRIO DE MINAS E ENERGIA, 2016). As aplicações variam de acordo com a geração da escória, mas são basicamente utilizados na composição de cimento e concreto, tijolos, construção de rodovias e aterros (LI et al., 2014). Já na Europa, além dos usos já citados, também há aplicações em engenharia hidráulica, fertilizantes, e uso interno em processos metalúrgicos (EUROSLAG, 2012). A Alemanha através do estudo de análise da substituição de subprodutos industriais da produção de aço como matérias-primas na construção de estradas (CUTEC, 2017), apresenta justificativas técnicas como emissão de poluentes e impacto no clima para uso dos resíduos na construção de rodovias. Já na França, Houze (2014) em sua tese de doutorado realiza o estudo da caracterização de escória na indústria do aço e produção de ligas de silício-manganês, avaliando o potencial uso da escória em possíveis destinações. Na Austrália e Ásia, há opções interessantes como lã de rocha, drenos para tratamento de águas subterrâneas e geopolímero. No Japão, os empregos das escórias têm sido feitos praticamente dentro do que já foi listado: rodovia, cimento, melhora de solo, agregado para concreto entre outras (NIPPON SLAG ASSOCIATION, 2015). Nos Estados Unidos, a escória tem sido empregada também como lastro de ferrovia, construção de diques, controle de erosão, estruturas de contenção, entre outras soluções.

No Brasil, estudos como aqueles desenvolvidos por Nóbrega (2007), Rodrigues (2007), Buitrago (2016), Oliveira (2013) e John et al. (2000) mostram que o país tem se dedicado a utilizar o agregado artificial em estruturas de engenharia como rodovias e ferrovias, assim como na produção de cimento. Rodrigues (2007) em seu trabalho sobre a caracterização e avaliação da expansibilidade de escórias de aciaria LD (Linz e Donawitz) não tratadas e tratadas, deixa evidente que a escória de aciaria possui características geotécnicas tão boas quanto às das rochas, porém sua expansibilidade se faz como ponto crítico na sua utilização. Como soluções para este problema, existem métodos para tratar, aplicados à escória de aciaria, que podem acelerar as reações de hidratação. A avaliação deste potencial é de grande relevância para determinar a efetividade do tratamento realizado.

Com isto em vista, Rodrigues (2007) caracterizou as propriedades físicas e microestruturais da escória de aciaria, e também avaliou o potencial de expansão deste material quando exposto apenas ao tempo, e exposto ao tempo com molhagem e aeração. Para isto foram utilizados ensaios já consagrados na área de pavimentação, como granulometria, abrasão Los Angeles, umidade entre outros. Já para a microestrutura foram utilizados análise química, microscopia eletrônica de varredura e difração de raios X. Para avaliação da expansão, foi adotado o método Steam Test. Finalmente, os resultados dos testes mencionados demonstraram que é viável a utilização da escória nas estruturas de pavimentação. Porém, os resultados do teste de expansão, revelam que nenhum dos tratamentos estudados se mostra eficiente, adotando-se o limite de aceitação de $5 \%$ e período de ensaio de 7 dias. 
Nóbrega (2007) trata em seu trabalho sobre caracterização mecânica de misturas asfálticas utilizando como agregado a escória de ferroliga de manganês, da região de Simões Filho - BA. Inicialmente, a escória foi caracterizada física, mecânica e quimicamente, conforme descrito nas normas de especificação de materiais 260/94 e 262/94 do DNER. De forma complementar, foram realizados os ensaios de Microscopia Eletrônica de Varredura (MEV), Energia Dispersiva de Raio X (EDS) para determinar a forma e a composição química dos materiais. Além disso, analisou o impacto ambiental através dos ensaios de solubilidade e lixiviação. Finalmente, devido ao conhecido problema relativo à expansão das escórias, foi executado o ensaio conforme o Pensylvania Test Material (PTM 130). Uma vez caracterizado, o material foi misturado à brita, pó de pedra e CAP50/60 (atual CAP 50/70) para confecção de Concreto Betuminoso Usinado a Quente - CBUQ. Além dos corpos de prova produzidos em laboratório, foram retiradas para análise amostras em campo de trecho executado com emprego da mistura na avenida Dom João VI, realizado pela Prefeitura de Salvador/BA. Finalmente, os resultados técnicos validaram o uso da escória de ferroliga de manganês para emprego em revestimento asfáltico, e os ensaios ambientais mostraram que a escória é classificada como Classe II - não inerte.

Oliveira (2013) em seu trabalho sobre a caracterização da escória de ferro silício-manganês para aplicação como agregado em pavimentação ferroviária, realizou a caracterização física, mecânica, química, mineralógica, ambiental e elétrica da escória siderúrgica de ferro silício-manganês produzida na região do quadrilátero ferrífero de Minas Gerais. Como resultado, o material analisado apresentou valores superiores aos limites mínimos prescritos pelas normas técnicas nacionais e internacionais, demostrando que a escória de ferro silício-manganês é um ótimo substituto dos materiais rochosos utilizados para lastro ferroviário.

Já Buitrago (2016) tratando da aplicabilidade do agregado siderúrgico açobrita misturado com solo em camadas de pavimento rodoviário, utilizou misturas com diferentes percentuais de solo e agregado: 70\% de agregado $+30 \%$ de solo, $80 \%$ de agregado $+20 \%$ de solo, $90 \%$ de agregado $+10 \%$ de solo. Tanto a escória, neste trabalho chamado de agregado siderúrgico, justamente na tentativa de tornar o resíduo num coproduto, quanto o solo e as misturas foram caracterizados física e mecanicamente. Além disso, o potencial expansivo do agregado foi analisado pelo método DNIT-ME 113/2009, conhecido internacionalmente como PTM 130/78. Como resultado, a escória foi avaliada como que apresentando características adequadas para uso como material de pavimentação, principalmente por obter controle em sua expansão; e acerca das misturas, as mesmas apresentaram desempenho satisfatório, tendo conformidade granulométrica, expansão controlada e altos valores de Índice de Suporte Califórnia, sendo aplicável como material de base de pavimentos rodoviários.

A consolidação do uso da escória como coproduto se mostra através das normas criadas para padronizarem sua utilização. Seja através da NBR 5735 - Cimento Portland de alto-forno de 1991; seja na norma DNIT-113/2009 Pavimentação Rodoviária - Agregado Artificial - Avaliação do potencial de expansão de escória de aciaria; também nas normas DNIT 114/2009 e DNIT 115/2009 que tratam do uso da escória (ACERITA) nas estruturas de base e sub-base rodoviária; e, por fim, nas recentes normas para pavimentação rodoviária como a DNIT- 406/2017 - Pavimentação rodoviária - Base estabilizada granulometricamente com 
Açobrita ${ }^{\circledR}$, e a DNIT- 407/2017 - Pavimentação rodoviária - Sub-base estabilizada granulometricamente com Açobrita ${ }^{\circledR}$.

Sobre o material objeto deste estudo, a escória de ferro silício-manganês é produzida na região da cidade de Barbacena/MG, cidade localizada próxima ao quadrilátero ferrífero mineiro. Sendo gerada durante o processo de produção da ferroliga nos fornos elétricos a arco submerso (EAF). Trata-se do resíduo de uma ferroliga, ou seja, um insumo essencial utilizado na indústria siderúrgica, tanto nos processos básicos como na refinada agregação de propriedades e valor aos aços especiais (OLIVEIRA, 2013). As ferroligas são ligas de ferro com outros metais, nos quais o teor do metal é maior que o teor de ferro, cujo objetivo é conferir determinadas propriedades ao aço. São alguns metais utilizados: níquel, manganês, cromo, tungstênio, nióbio e titânio. Outro ponto relevante é que a prática usual é adicionar às ferroligas ao invés do metal puro para a produção de aço, uma vez que aquela tem um custo menor (OLIVEIRA, 2013). O manganês, acrescentado na forma de ferroliga, auxilia no refinamento da estrutura de grãos, aumentando a resistência mecânica e melhorando a temperabilidade e a ductibilidade do aço (CHIAVERINI, 1990). Portanto, este estudo visa apresentar parâmetros técnicos no intuito de avaliar as possibilidades de uso da escória de ferro silício-manganês em estruturas de pavimento flexível rodoviário.

\section{Granulometria}

Iniciando pela granulometria, esta trata da distribuição, com sua quantificação em peso, por tamanho das partículas de uma amostra que compõe um agregado. Essa distribuição é definida ao se passar a amostra por uma série de peneiras, cujas malhas estão normatizadas, e o resultado desse processo posteriormente é representado graficamente através da Curva Granulométrica. A curva gerada é então comparada com intervalos denominados Faixas Granulométricas, as quais tem o objetivo de assegurar a resistência através do intertravamento dos grãos. No presente estudo, o material para análise, foi processado utilizando a série normal de peneiras: $19 \mathrm{~mm}, 9.5 \mathrm{~mm}, 4.8 \mathrm{~mm}, 2.4 \mathrm{~mm}, 1.2 \mathrm{~mm}, 0.60 \mathrm{~mm}, 0.30 \mathrm{~mm}, 0.150 \mathrm{~mm}$. Devido ao custo associado a britagem, o material tem sido produzido com granulometrias maiores. As equações [1] e [2] utilizadas para esta análise são as seguintes:

$$
\begin{gathered}
\% \text { Retido }=\frac{\text { Peso Retido }}{\text { Total do peso da amostra }} \\
\% \text { Passado }=100 \%-\% \text { Retido Acumulado }
\end{gathered}
$$

\section{Densidade aparente do agregado graúdo e absorção}

A densidade aparente do agregado, Equação [3], obtido pela relação entre a massa do agregado seco e seu volume, é o parâmetro a ser utilizado como referência para determinar a massa de material a ser empregado seja em mistura asfáltica, seja em camadas de base e sub-base. Já a absorção, Equação (4), dada pelo aumento de massa do agregado devido ao preenchimento de seus poros permeáveis por água, permite analisar a porosidade do agregado, tanto para verificar sua resistência quanto para mensurar o consumo de ligante (CAP - cimento asfáltico de petróleo, emulsão), quando usado como agregado em misturas asfálticas. 


$$
D_{a p}=\frac{M_{S}}{M_{h}-L}
$$

$D_{a p}$ é a densidade aparente; $M_{s}$ é a massa, ao ar, do agregado seco em estufa, em g; $M_{h}$ é a massa, ao ar, do agregado na condição saturada superfície seca, em g; $L$ leitura na balança correspondente ao agregado submerso, em g (pesagem hidrostática).

Quanto à absorção, foi empregada a expressão [4]:

$$
a=\frac{M_{h}-M_{S}}{M_{S}} \times 100
$$

$a$ é a absorção, em percentual.

\section{Determinação da Abrasão Los Angeles}

Já a determinação da abrasão Los Angeles, consiste na determinação da resistência ao desgaste superficial dos grãos de agregado quando submetido ao atrito. Logo, o ensaio mensura a capacidade do agregado não se alterar quando manuseado. O ensaio consiste em depositar determinada massa de agregado, com granulometria conhecida, dentro do tambor cilíndrico juntamente com esferas de ferro fundido. Posteriormente, são provocadas as revoluções especificadas em norma e, após retirado do tambor, o material resultante do processo é lavado na peneira $\# 1,7 \mathrm{~mm}$, levando-o à estufa posteriormente. Finalmente, procede-se a pesagem. Para este estudo, foi utilizada a Graduação A da norma DNER-ME 035/98 - Determinação da Abrasão Los Angeles, conforme Figura 1.

\begin{tabular}{c|c}
\hline $\begin{array}{c}\text { Peneiras } \\
\text { Aberturas em mm }\end{array}$ & $\begin{array}{c}\text { Amostras } \\
\text { Pesos parciais em gramas }\end{array}$ \\
\hline Retido na & Graduação A \\
25 & $1250 \pm 25$ \\
19 & $1250 \pm 25$ \\
12,5 & $1250 \pm 25$ \\
9,5 & $1250 \pm 25$ \\
Peso Total & $5000 \pm 10$ \\
Número de revoluções no tambor & 500 \\
\hline
\end{tabular}

Figura 1: Amostras para ensaio de Abrasão Los Angeles. Fonte: DNER-ME 035/98 - Determinação da Abrasão Los Angeles.

\section{Análise Mineralógica}

Para análise mineralógica, foi empregada a espectroscopia de energia dispersiva de raios X (EDS Energy Dispersive X-Ray Spectroscopy) que consiste numa microanálise a qual permite a obtenção de informações químicas em áreas da ordem de micrometros, sendo estas (qualitativas e quantitativas) obtidas pela detecção dos raios-X resultantes da interação entre o feixe primário e a amostra. Na análise de EDS é usado um material semicondutor para detectar os raios-X e um analisador multicanal, que converte a energia de raios-X em uma contagem eletrônica; resultando num espectro representativo da análise química da amostra. O equipamento utilizado foi o JEOL 5800LV. 


\section{Microscopia Eletrônica de Varredura (MEV)}

Sobre a análise da microestrutura, foi utilizada a Microscopia Eletrônica de Varredura (MEV), no qual foram geradas imagens com aumento de até $8000 x$. Os resultados desse ensaio permitem analisar a forma e dimensão dos grãos, assim como a disposição dos mesmos na superfície da amostra, possibilitando também uma percepção melhor dos vazios presentes no material. O uso em conjunto do EDS com o MEV é de grande importância na caracterização petrográfica e estudo petrológico nas geociências, pois enquanto o primeiro permite a identificação dos elementos que compõe a amostra, o segundo proporciona nítidas imagens da microestrutura.

Índice de Degradação após compactação Proctor e Determinação da perda ao choque no aparelho Treton

O Índice de Degradação após compactação Proctor e a determinação da perda ao choque no aparelho Treton, visam analisar as características quanto à tenacidade, resistência abrasiva e até mesmo de dureza dos agregados. Além disso, em virtude de experiências em que agregados com abrasão Los Angeles acima do limite superior foram usados e o desempenho ao longo dos anos mostrou-se satisfatório quanto a esse parâmetro, o DNER passou a recomendar a execução desses outros ensaios a serem conduzidos nos agregados que apresentassem o valor de abrasão Los Angeles acima do limite superior especificado. A indicação desses ensaios assim como valores limites a serem adotados para os mesmos foram sugeridos em pesquisa do IPR-DNER (BERNUCCI et al., 2010). Apesar do valor encontrado para a escória de ferro silíciomanganês ter sido satisfatório para o ensaio de abrasão, entendeu-se ser relevante validar os resultados por meio de outras análises devido ao aspecto vítreo de parte do material, e sua microestrutura similar a planos de clivagem. A Degradação após a compactação Proctor foi calculada conforme a expressão [5]:

$$
I D_{p}=\frac{\sum D}{5}
$$

$I D_{p}$ é o Índice de Degradação, adimensional;
$D$ é a diferença entre a média das amostras e a granulometria.

\section{Aggregate Imaging System (AIMS)}

O Sistema de análise de agregados por imagens digitalizadas (AIMS) foi desenvolvido para capturar imagens e analisar a forma de uma ampla gama de tipos e tamanhos de agregados, a fim de analisar seu uso em misturas de asfalto, concreto cimento hidráulico e camadas de pavimentos (AL-ROUSAN, 2004). Este sistema é utilizado para analisar a forma, textura e angularidade de agregados (conforme Figura 2), sendo a nova metodologia para a classificação de agregados baseada na distribuição das características de forma.

Angularidade mede a diferença entre um raio de partículas numa determinada direção e uma elipse equivalente. A elipse equivalente tem a mesma relação de aspecto com a partícula, mas não tem a angularidade. Esfericidade - ou forma de partículas (MASAD et al., 2005) ou forma (MASAD et al., 2014) - é o parâmetro que classifica os agregados quanto à sua forma. Este é um parâmetro adimensional que varia entre 0 e 1, tendo em conta os agregados com índices perto de 1 com esfericidade ótima, e sendo os agregados com índices próximos de 0 com baixa esfericidade, ou seja, são mais lamelar que esféricos (MASAD 
et al., 2002). Textura da superfície é usada para descrever a irregularidade da superfície que atua numa escala muito pequena, que pouco afeta a forma geral ou angularidade (MASAD et al., 2005). A Figura 3 mostra os valores limites e a classificação para as propriedades de forma do agregado.

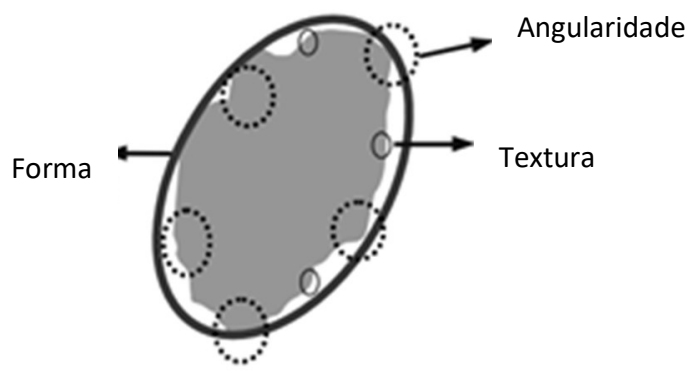

Figura 2: Componentes de Propriedades de forma de agregado: Forma, Angularidade e Textura. Fonte: (MASAD et al., 2005).

\begin{tabular}{cccccc}
\hline Propriedade & \multicolumn{5}{c}{ Valores - limite / Classificação } \\
\hline $\begin{array}{c}\text { Esfericidade } \\
\text { (graúdo) }\end{array}$ & $\begin{array}{c}\text { Achatado/ } \\
\text { Alongado }\end{array}$ & Baixa esfericidade & $\begin{array}{c}\text { Esfericidade } \\
\text { moderada }\end{array}$ & $\begin{array}{c}\text { Alta } \\
\text { esfericidade }\end{array}$ & - \\
Angularidade & $<2100$ & $2100-4000$ & $4000-5400$ & $>5400$ & - \\
$\begin{array}{c}\text { (miúdo e graúdo) } \\
\text { Textura }\end{array}$ & Arredondado & Subarredondado & Subangular & Angular & - \\
$\begin{array}{c}\text { Superficial } \\
\text { (graúdo) }\end{array}$ & Polido & Macio & Baixa rugosidade & $\begin{array}{c}\text { Rugosidade } \\
\text { moderada }\end{array}$ & $\begin{array}{c}\text { Alta } \\
\text { rugosidade }\end{array}$ \\
\hline
\end{tabular}

Figura 3: Valores limites e a Classificação para as propriedades de forma do agregado. Fonte: Adaptado Masad et al. (2002).

\section{RESULTADOS E DISCUSSÃO}

\section{Granulometria}

Utilizando as normas DNER-PRO 120/97 - Coleta de amostra de agregados e DNER-PRO 199/96 Redução de amostra de campo de agregados para ensaios de laboratório, procedeu-se a seleção de quatro amostras representativas, sendo realizado o processo de peneiramento, seguido da pesagem dos materiais retidos nas respectivas peneiras. Devido ao fator econômico do custo de britagem, o material vem sendo reduzido a diâmetros de agregado graúdo, uma vez que o objetivo da empresa tem sido apenas estocar este material em pilhas.

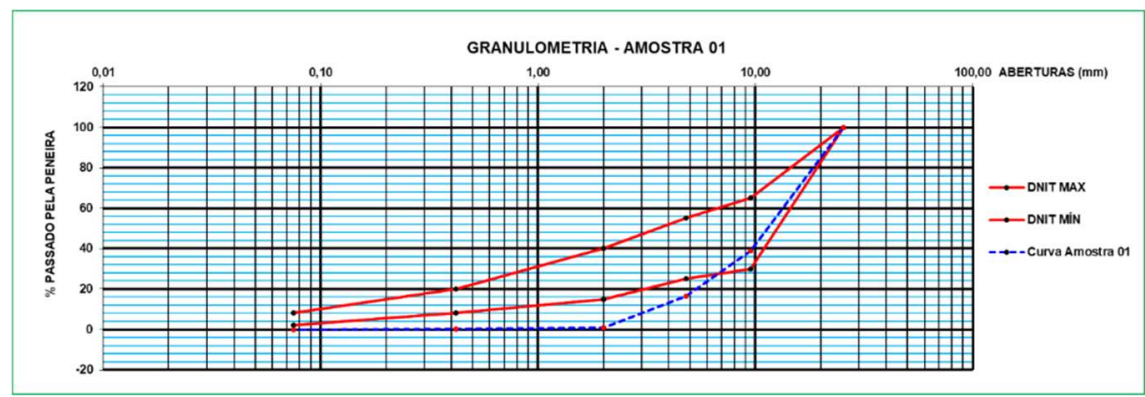




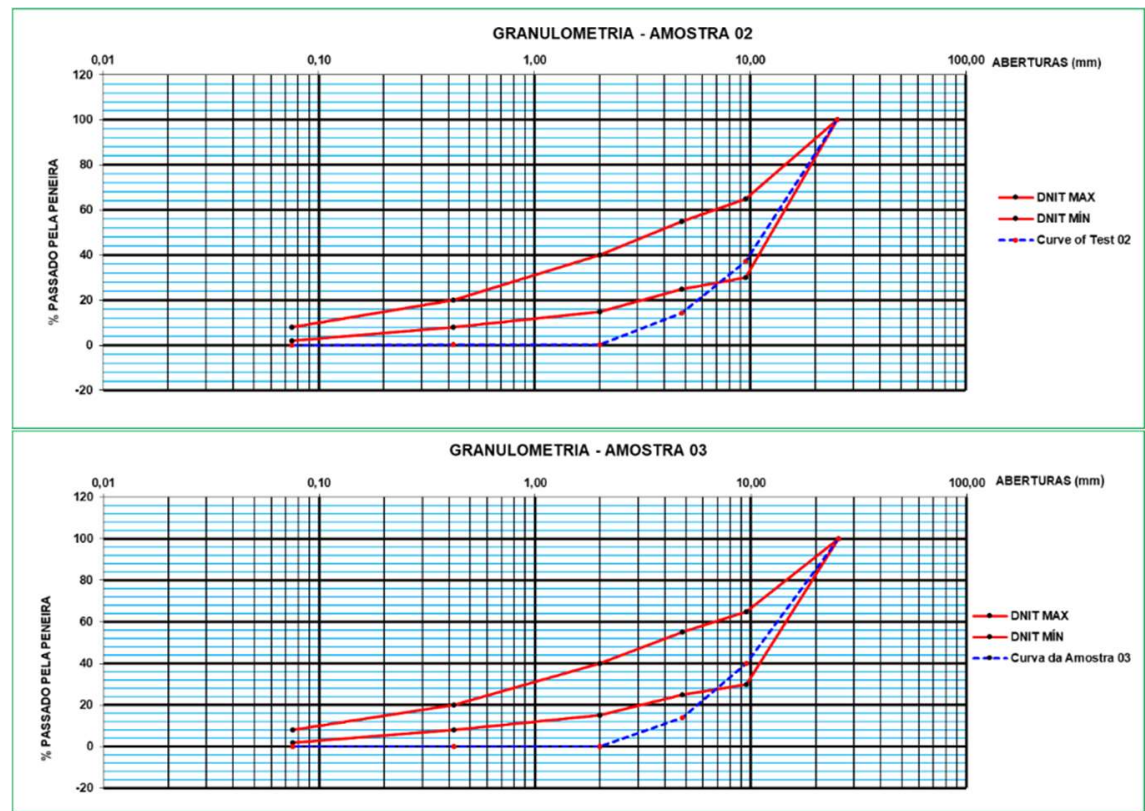

Figura 4: Resultados do Ensaio de Caracterização Granulométrica

Como referência, foi utilizada a Faixa A do DNIT (Base estabilizada granulometricamente - DNIT 141/2010). Como pode ser notada na Figura 4, a composição do material apresenta predominantemente grãos graúdos, coerente com a política adotada pela empresa geradora do resíduo em reduzir custo com britagem. Entende-se que, caso não se viabilize uma forma de reduzir os grãos, uma opção viável para o uso deste material seria o emprego de mistura com solo.

\section{Densidade aparente do agregado graúdo e absorção}

Conforme a norma DNER-ME 081/98, a densidade do agregado graúdo encontrada foi de $2,94 \mathrm{~g} / \mathrm{cm}^{3}$ e a absorção de $0,44 \%$. Acerca destes resultados, a densidade se encontra muito próxima, $2,96 \mathrm{~g} / \mathrm{cm}^{3}$, quando comparado com a escória de ferro silício-manganês pesquisada por Oliveira (2013), cujo material também pertence à mesma empresa geradora do resíduo, entretanto, numa unidade localizada em outra cidade de Minas Gerais. Ainda quando comparado com os resultados obtidos por Nóbrega (2007), em Salvador/BA, que analisou a escória de ferroliga manganês para uso em revestimento asfáltico, o valor encontrado de $2,92 \mathrm{~g} / \mathrm{cm}^{3}$, para granulometria de 0 a 3/8", ainda se mostra coerente.

Finalmente, quando comparado com britas granito-gnaisse provenientes do Estado do Rio de Janeiro, conforme Lima (2016), cujos os valores se mostram como 2,62 e 2,64 g/ $\mathrm{cm}^{3}$, é possível perceber que o material possui valor acima do agregado natural. Entretanto, a escória de ferro silício-manganês possui menor densidade quando comparados com a escória de aciaria, cujos valores se apresentam acima de $3,0 \mathrm{~g} / \mathrm{cm}^{3}$, conforme Rodrigues (2007). Quanto à absorção, os valores encontrados por Oliveira (2013) e Nóbrega (2007) se encontram superiores a 1,0\%.

\section{Determinação da Abrasão Los Angeles}

Conforme a Figura 5, é possível notar que o valor de 25,53\% para abrasão se encontra dentro dos limites estabelecidos pelas normas DNIT 141/10 - Base estabilizada granulometricamente, DNIT 406/17 - 
Base estabilizada granulometricamente com Açobrita ${ }^{\circledR}$ e DNIT 407/17 - Sub-base estabilizada granulometricamente com Açobrita $^{\circledR}$, as quais definem como $55 \%$ a abrasão máxima para o agregado a ser empregado em camadas de pavimento. Além disso, a escória de ferro silício-manganês encontra-se adequada também quando utilizadas as normas DNIT 115/09 - Base estabilizada granulometricamente com escória de aciaria - ACERITA ${ }^{\circledR}$ e DNIT 114/09 - Sub-base estabilizada granulometricamente com escória de aciaria - ACERITA ${ }^{\oplus}$, as quais definem o limite de abrasão como $40 \%$.

\begin{tabular}{ccccc}
\hline Amostra & $\begin{array}{c}\text { Peso Inicial } \\
\text { (g) }\end{array}$ & Peso final (g) & Abrasão (\%) & Média \\
\hline 01 & 5000 & $3.732,9$ & $25,34 \%$ & \\
02 & 5000 & 3713,7 & $25,73 \%$ & $25,53 \%$ \\
03 & 5000 & $3.724,2$ & $25,52 \%$ & \\
\hline
\end{tabular}

Figura 5: Resultados dos ensaios de Abrasão Los Angeles.

\section{Análise Mineralógica}

Existem dois tipos de escórias - Figura 6 - formadas pelos processos de produção de FeSiMn (ferro silício-manganês): escória rica, que é ácida, tem alto teor de $\mathrm{Mn}$ (acima de 40\%) e quantidade de fósforo muito baixa, sendo reciclável e reutilizada como entrada na produção da liga de FeSiMn. Esta escória (rica) apresenta características de vitrificação, o que diminui sua resistência, além de ser prudente a cautela no manuseio. Já a escória pobre, que é básica, tem um baixo teor de manganês ( $\mathrm{MnO}<20 \%$ ) e cerca de $30 \%$ de Si (OLSEN et al., 2004).
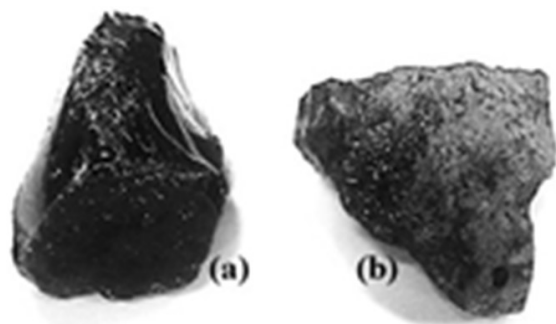

Figura 6: Escória de ferro silício-manganês (a) rica e (b) pobre. Fonte: Oliveira (2013).

Devido à heterogeneidade do material, foi realizado o ensaio em duas regiões distintas do agregado, as quais encontram-se assinaladas pelos dois retângulos na Figura 7. Os gráficos da Figura 8 apresentam os valores dos elementos encontrados. Conforme o resultado obtido, os principais elementos que formam a escória de ferro silício-manganês são o carbono, o oxigênio e o silício. Em sequência vem o cálcio, o manganês e o alumínio. Os percentuais estão apresentados na Figura 9. Entende-se ser relevante realizar o ensaio de Termogravimetria (TGA) para se explicitar como esses elementos estão agrupados em compostos, e assim definir de forma mais clara a composição mineralógica da escória.

A determinação mineralógica se faz relevante uma vez que, conforme Oliveira (2013), O grande problema na utilização das escórias em obras de pavimento se dá pelo fato de as escórias possuírem características expansivas devido, principalmente, à hidratação de cal livre $(\mathrm{CaO})$, do periclásio $(\mathrm{MgO})$ e à corrosão e oxidação do ferro metálico residual, gerando tensões internas que originam trincas e até resultam 
na fragmentação do material, ou seja, numa expansão destrutiva. Logo, a determinação da quantidade destes elementos ajuda a prever o potencial de expansão do material.

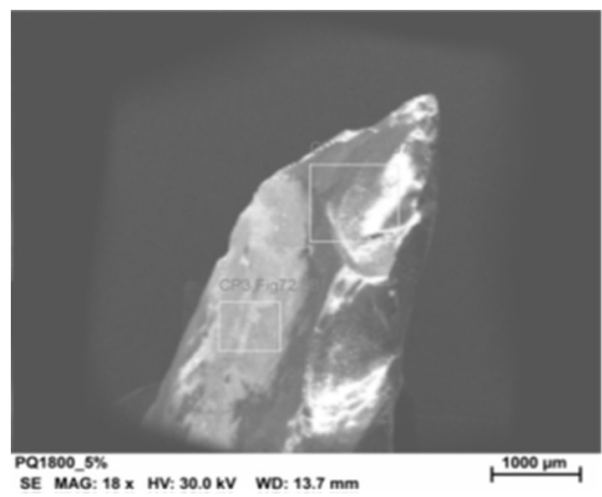

Figura 7: Microfotografia de amostra de escória de ferro silício-manganês.
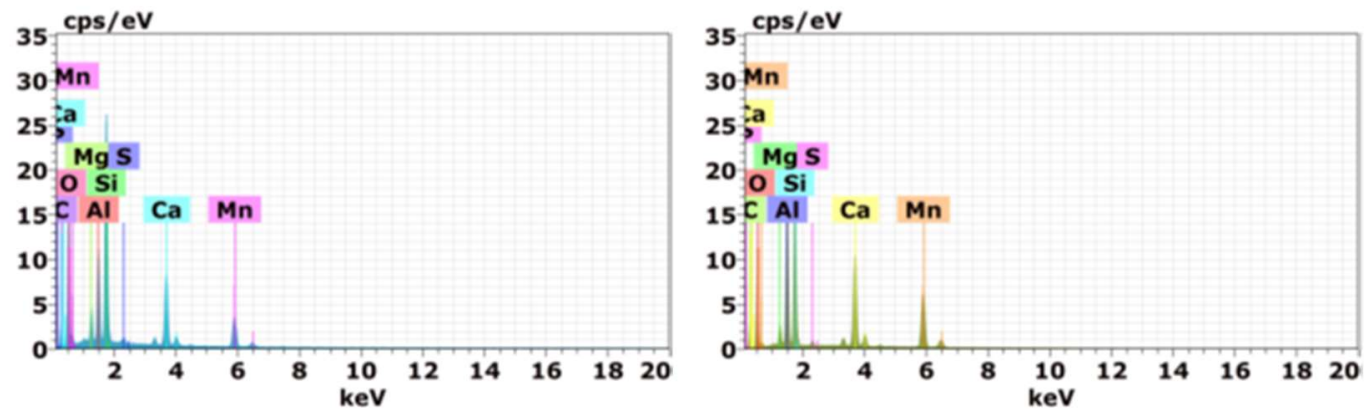

Figura 8: CP3 - Fig 7237 (Área Superior) - Esquerda; CP3 - Fig 7238 (Área Inferior) - Direita.

\begin{tabular}{lcc}
\hline Elemento & Leitura 01 & Leitura 02 \\
\hline Carbono & $13,9 \%$ & $18,1 \%$ \\
Oxigênio & $49,4 \%$ & $31,9 \%$ \\
Magnésio & $2,3 \%$ & $1,5 \%$ \\
Alumínio & $5,8 \%$ & $11,0 \%$ \\
Silício & $14,4 \%$ & $12,2 \%$ \\
Enxofre & $0,1 \%$ & $0,2 \%$ \\
Cálcio & $7,7 \%$ & $11,4 \%$ \\
Manganês & $6,4 \%$ & $13,7 \%$ \\
\hline
\end{tabular}

Figura 9: Composição química, por elementos, da escória de ferro silício-manganês.

Com isto em vista, uma vez que Nóbrega (2007) utiliza também a escória de ferro silício-manganês, o qual foi referenciado por Oliveira (2013) em seu trabalho, é possível adotar o valor encontrado para o ensaio PTM 130/78 (Pensylvania Test Method) para o material aqui em estudo. Como pode ser visto na Figura 10, a expansão pode ser considerada como $0 \%$.

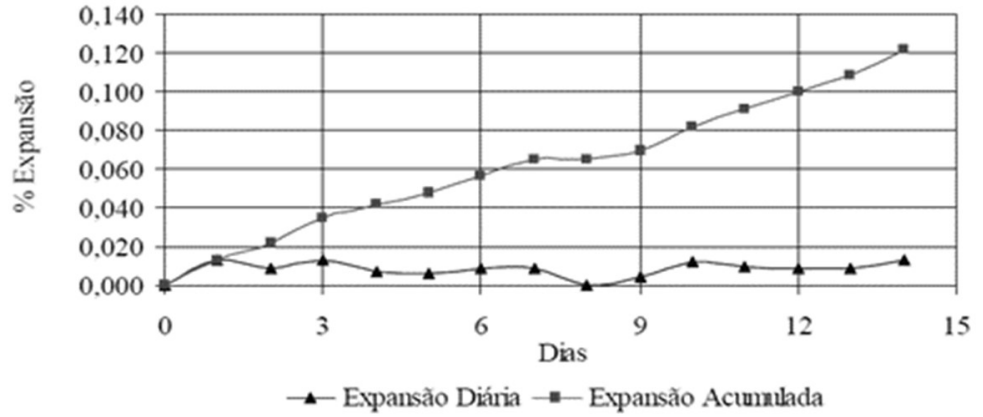

Figura 10: Expansão através do ensaio PTM 130/78. Fonte: Nóbrega (2007). 
Sobre o possível impacto ambiental da disposição da escória de ferro silício-manganês no meio ambiente, Oliveira (2013) apresenta o Ofício n³06/2010/NLA/SUPES/IBAMA/MG que aprova a utilização escória de ferro silício-manganês como lastro ferroviário, em se tratando da caracterização e classificação ambiental. Ainda nesse trabalho, a amostra da escória de ferro silício-manganês foi classificada como Classe II A (não perigoso - não inerte) por apresentar teor de Alumínio solubilizado acima do limite máximo permitido.

\section{Microscopia Eletrônica de Varredura (MEV)}

É importante salientar que a escória em estudo apresenta características distintas das escórias de aciaria e de alto forno, conforme Figura 11. As principais diferenças residem no fato tanto da coloração esverdeada, superfície lisa, aspecto vítreo e pouca quantidade de finos. Algumas dessas características podem ser nitidamente notadas quando comparadas imagens das microestruturas dos dois materiais, conforme as Figuras 12, 13 e 14. Por se tratar de resíduo de processo de mistura de compostos, o material apresenta certa heterogeneidade.

A parte mais externa, ou seja, àquela que possui maior contato com o ar e umidade apresenta certa porosidade. Já a parte mais interna, logo com menor exposição às intempéries, tem a superfície lisa e quantidade de vazios nitidamente menor, justificando o aspecto mais compacto do material. Além disso, é possível notar que o material é formado por meio de camadas (estrutura similar a planos de clivagem), sugerindo que a ruptura acontece por cisalhamento.

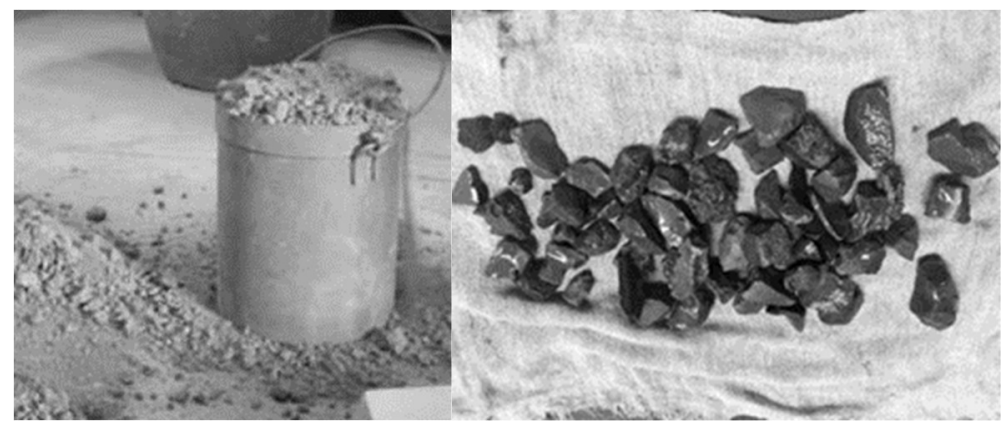

Figura 11: Diferença de forma e superfície: à direita, escória de aciaria; à esquerda, escória de ferro silício-manganês. Fonte: Rodrigues (2007).

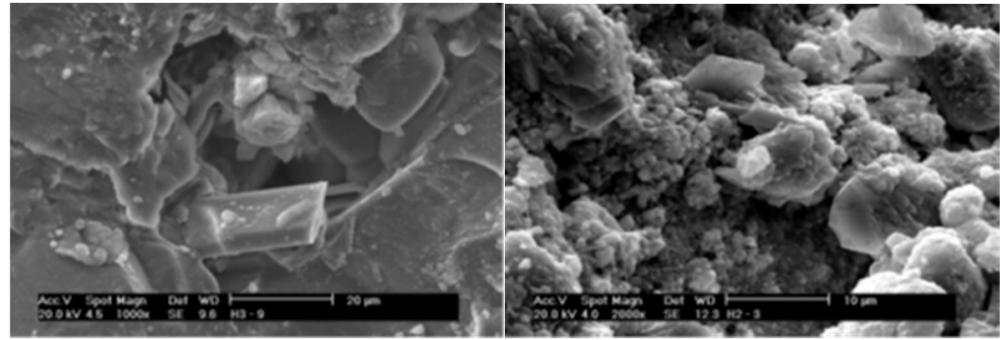

Figura 12: Imagens da microestrutura de escória de aciaria (1000x e 2000x). Fonte: Rodrigues (2007) 


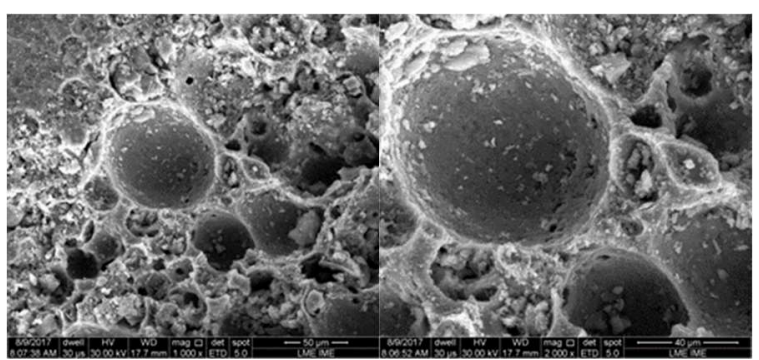

Figura 13: Imagens da microestrutura da escória de ferro silício-manganês - amostra mais exposta ao ambiente (1000x e 2000x).

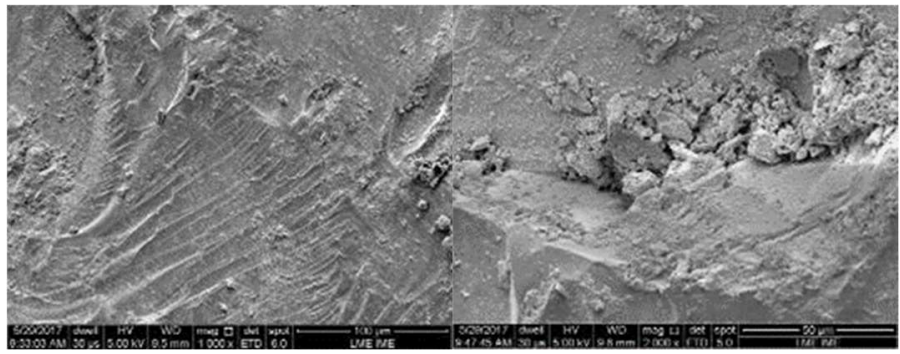

Figura 14: Imagens da microestrutura da escória de ferro silício-manganês - amostra menos exposta ao ambiente (1000x e 2000x).

\section{Índice de Degradação após compactação Proctor e perda por choque no equipamento Treton}

O ensaio de índice de degradação foi realizado após a execução do ensaio de Índice de Suporte Califórnia - ISC, sendo o agregado posteriormente passado novamente nas peneiras utilizadas para separação da amostra. Como resultado, obteve-se um IDp de 0,26, ou seja, o material degradado nas peneiras com diâmetros maiores, ficou retido nas peneiras menores. Como pode ser visto na Tabela 1 a seguir:

Tabela 1: Resumo com os resultados do IDp.

\begin{tabular}{|c|c|c|c|c|c|c|c|c|}
\hline \multirow{3}{*}{ Peneiras } & \multicolumn{8}{|l|}{ \% Passando nas peneiras } \\
\hline & \multirow{2}{*}{ Granulometria original padronizada } & \multicolumn{7}{|c|}{ Granulometria após a compactação } \\
\hline & & AM 1 & AM 2 & AM 3 & AM 4 & AM 5 & Média & D \\
\hline $19 \mathrm{~mm}$ & 68 & 83 & 78 & 79 & 84 & 86 & 82 & 13,92 \\
\hline $12,5 \mathrm{~mm}$ & 64 & 68 & 63 & 67 & 69 & 71 & 68 & 3,67 \\
\hline $9 \mathrm{~mm}$ & 62 & 59 & 54 & 57 & 60 & 61 & 58 & $-3,78$ \\
\hline no 4 & 60 & 48 & 44 & 46 & 48 & 50 & 47 & $-12,77$ \\
\hline \multicolumn{8}{|l|}{ Soma D } & $-12,77$ \\
\hline & & & & & & & IDp & 1,04 \\
\hline
\end{tabular}

Tendo como referência o estudo de Métodos de Ensaios de Características Mecânicas e Valores de Aceitação de Agregados (IPR, 1998), cujo limite para IDp é igual a 6, é possível afirmar que o material é aceitável. A Tabela 1 ainda mostra que, de forma relativamente proporcional entre as amostras, o agregado graúdo (entre $19 \mathrm{~mm}$ e $12.5 \mathrm{~mm}$ ) assumiu tamanhos de grãos menores, de $12.5 \mathrm{~mm}$ a $4.8 \mathrm{~mm}$. É interessante correlacionar, que as maiores degradações ocorreram nas amostras com o que pode ser entendido como a umidade ideal (Amostra 5), seguido das amostras com menor umidade (Amostras 1 e 4) e, finalmente, menores perdas de massa nos agregados maiores umidades (Amostras 2 e 3). É interessante observar que a curva definida pela comparação Umidade x Degradação apresenta a forma similar à curva de compactação (umidade ótima $x$ densidade máxima), conforme a Figura 15. Finalmente, nota-se que a situação que ocorre a maior degradação é precisamente nas condições ideais para a execução do pavimento. Desta forma, é prudente tomar as precauções necessárias para proteger os grãos quando a compactação for realizada. 

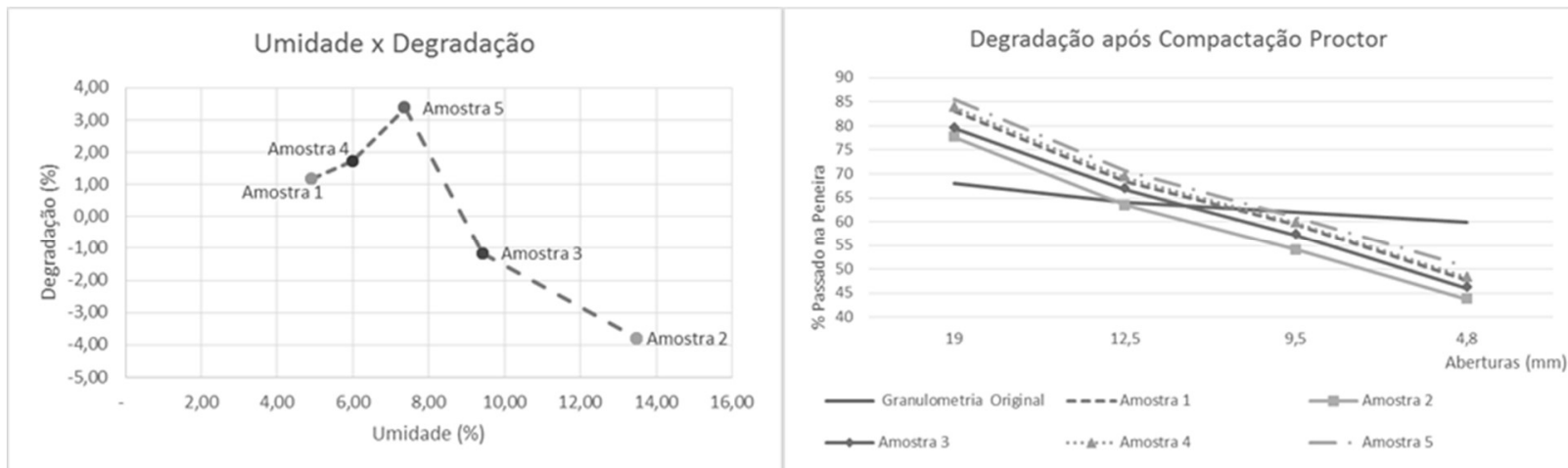

Figura 15: O gráfico à esquerda mostra a granulometria das amostras após a compactação Proctor. O segundo gráfico, à direita, mostra a relação entre umidade e degradação.

Uma análise semelhante foi realizada sobre a caracterização geotécnica de escórias de silíciomanganês para aplicações de engenharia civil, onde Kumar et al. (2013) apresentou os resultados da granulometria da escória de silício-manganês antes e após a compactação. No estudo, a porcentagem de partículas maiores diminuiu de $15 \%$ para $0 \%$, a areia aumentou de $84 \%$ para $97 \%$, e as finas de $1 \%$ para $3 \%$.

Para o ensaio com o equipamento de Treton, a perda por choque ficou em $8,88 \%$. Tendo como referência o valor de 60\% o valor máximo admissível de perda, descrito pelo IPR (1998) acerca de Métodos de Ensaio para determinação de características mecânicas de agregados e valores de aceitação no livro Pavimentação Asfáltica: Formação Básica para Engenheiros (BERNUCCI et al., 2010), o material é aceitável para uso em pavimentos.

\section{Aggregate Imaging System (AIMS)}

De acordo com o Gráfico de Distribuição de Angularidade, o material, em geral, pode ser classificado como sub-arredondado, uma vez que mais de $90 \%$ apresentam índice de angularidade superior a 2100 , sendo as amostras classificadas como moderadas em 52\%. De acordo com as especificações técnicas do Departamento de Estradas de São Paulo (Brasil) ET-DE-P00 / 008 e DNER-ME086 / 94, a esfericidade (índice de forma) do agregado deve ter um índice igual ou superior a 0,50. Como pode ser visto no Gráfico de Distribuição de Esfericidade, mais de $90 \%$ das amostras atendem a este requisito, exceto o agregado com 4,75mm. Além disso, o padrão recomenda que menos de $10 \%$ sejam de partículas lamelares, ou seja, o agregado analisado também atende a esta especificação.

Sobre o Gráfico de Distribuição de Textura, esta propriedade está intimamente ligada à força de fricção e maior a rugosidade da superfície, logo quanto os valores deste parâmetro maior será a resistência à deformação permanente, uma vez que a força de friç̧ão entre os grãos será aumentada. Pode-se dizer que um material granular é mais áspero após o esmagamento, em geral (LIMA, 2016). Os resultados mostram que mais de $70 \%$ é superior a 200 e 55\% é classificado como moderado. Alguns estudos, como Lima (2016) e Tutumluer et al. (2008), foram feitos com o objetivo de estabelecer parâmetros de referência para angularidade e textura, que estão ligados à resistência. A Figura 16 abaixo mostra as propriedades da forma da escória de ferro silício-manganês. 

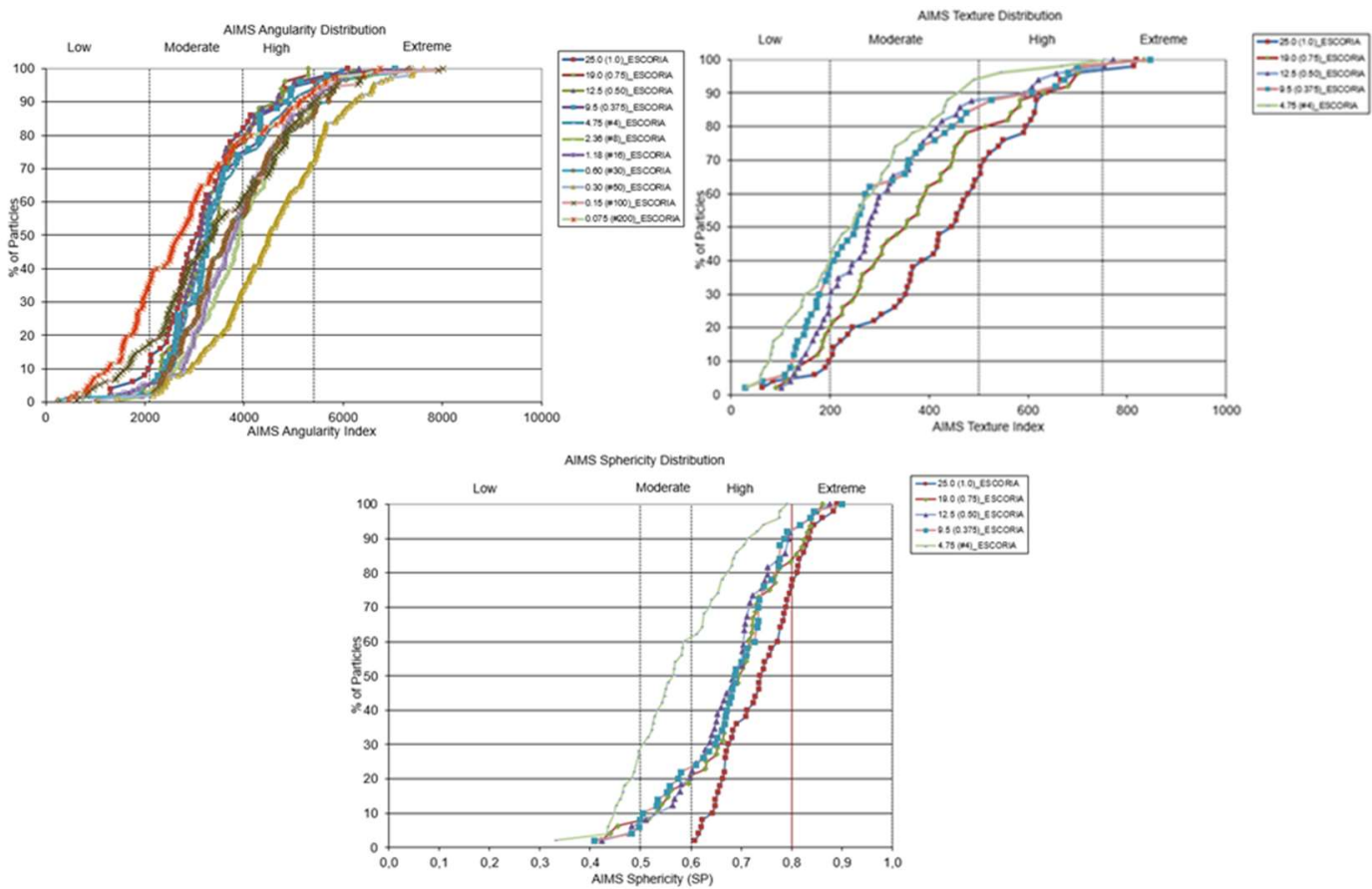

\section{CONCLUSÕES}

A granulometria tem predominantemente grãos graúdos, sendo interessante o uso do solo como forma de ajustar o tamanho do grão da escória de ferro silício-manganês para a curva granulométrica padronizada. Os valores de densidade aparente para agregado graúdo são semelhantes aos encontrados por outros autores e maiores que agregados graúdos naturais. A Determinação de Abrasão Los Angeles está de acordo com os padrões brasileiros para uso em base e sub-base. Sobre a Análise Mineralógica, a maior parte da escória de ferro de silício e manganês é composta por Carbono, Oxigênio e Silício. Seguido de cálcio, manganês e alumínio. Quanto à Expansão, de acordo com, o valor é igual a zero. Oliveira (2013) classificou o material como Classe II A (não perigoso, não inerte).

Através da Microscopia de Varredura Eletrônica é possível afirmar que a estrutura é mais compacta do que a escória de aciaria e é semelhante aos planos de clivagem. O AIMS mostra que: a angularidade é subarredondada; a esfericidade está de acordo com os valores do padrão brasileiro para uso em camadas de base e sub-base; e a textura é classificada como moderada. Sobre o índice de degradação após a compactação do Proctor e a perda de Choque no equipamento Treton, ambos os resultados para a escória de ferro silício-manganês estão dentro dos parâmetros definidos do Instituto de Pesquisas Rodoviárias - IPR para uso na estrutura do pavimento.

Finalmente, diante dos resultados apresentados pelos ensaios e métodos utilizados, entende-se que a escória de ferro silício-manganês tende a ser viável no emprego em camadas de pavimento rodoviário. Entende-se, entretanto, que ensaios para validação quanto à resistência mecânica, seja Índice de Suporte Califórnia e/ou Módulo de Resiliência, são importantes para avaliar o desempenho do material a ser empregado. Desta forma, o resíduo teria uma destinação ambientalmente adequada, haveria menor impacto ambiental com a redução na extração de agregados para aplicação na rodovia, além de possível redução de custos, seja na aquisição do material, seja no transporte do mesmo. 


\section{REFERÊNCIAS}

AL-ROUSAN, T. M.. Characterization of aggregate shape properties using a computer automated system. Thesis (Philosophiæ Doctor) - Texas A\&M University, 2004.

ARÊDES, M. L. A.. Avaliação do comportamento mecânico de misturas asfálticas utilizando resíduo do beneficiamento do minério de ferro. Dissertação (Mestrado) - Instituto Militar de Engenharia, Rio de Janeiro, 2016.

BERNUCCI, L. B.; MOTTA, L. M. G.; CERATTI, J. A. P.; SOARES, J. B.. Pavimentação asfáltica: Formação básica para engenheiros. São Paulo: Petrobrás, 2010.

BIRGISDÓTTIR, H.. Life cycle assessment model for road construction and use of residues from waste incineration. Thesis (Philosophiæ Doctor) - Institute of Environment \& Resources Technical University of Denmark, 2005.

BUITRAGO, N. D. T.. Aplicabilidade do agregado siderúrgico açobrita misturado com solo em camadas de pavimento rodoviário. Dissertação (Mestrado) - Universidade de Brasília, 2016.

CHIAVERINI, V.. Aços e ferros fundidos. 6 ed. São Paulo: Associação Brasileira de Metalurgia, Materiais e Mineração, 1990.

CUTEC. Cambridge University Technology and Enterprise Club. Bewertung der Substitution von industriellen Nebenprodukten der Stahlerzeugung durch Primärrohstoffe beim Einsatz im Straßen- und Wegebau. Berlim, 2017

EUROSLAG. The European Slag Association. Position Paper on the Status of Ferrous Slag. Berlim, 2012.

HOUZE, C.. Étude de la valorisation des laitiers de I'industrie sidérurgique et de production des alliages silico manganèse. Thesis (Philosophiæ Doctor) - Paris, 2014.

IPR. Instituto de Pesquisas Rodoviárias. Estudos e pesquisas de rochas de pedreiras para estabelecimento de critérios de qualidade frente às normas e procedimentos existentes e sua aceitação: Relatório final. Rio de Janeiro: ECL, 1998.

JOHN, V. M.; AGOPYAN, V.. Reciclagem de escória de alto forno no Brasil. Artigo técnico. São Paulo: Universidade de São Paulo, 2000.

KUMAR, K. R.; REDDY, C. N. V. S.. Geotechnical characterization of silico manganese slag for civil engineering applications. In: INTERNATIONAL YOUTH GEOTECHNICAL ENGINEERS CONFERENCE, 4. Anais. 2013.

LI, G.; GUO, M.. Current Development of Slag Valorisation in China. Wuhan University of Science and Technology, Pequim, v.5, n.3, p.317-325, 2014.

LIMA, C. D. A.. Estudo da deformação permanente de duas britas graduadas para uso em camadas de pavimentos. Dissertação (Mestrado) - Universidade Federal do Rio de Janeiro, 2016.
MARTINS, E.. Contabilidade de Custos. São Paulo: Atlas, 2010.

MASAD, E.; AL-ROUSAN, T.; BUTTON, J.; LITTLE, D.; TUTUMLUER, E.. Appendixes to NCHRP Report 555: Test Methods for Characterizing Aggregate Shape, Texture, and Angularity. Champaign: Texas Transportation Institute and University of Illinois as Urbana-Champaign, 2005.

MASAD, E.; OLCOTT, D.; WHITE, T.; TASHMAN, L.. Correlation of fine aggregate imaging shape indices with asphalt mixture performance. Champaign: Transportation Research Record, 2014.

MASAD, E.; JANDHYALA, V. K.; DASGUPTA, N.; SOMADEVAN, N.; SHASHIDHAR, N.. Characterization of Air Void Distribution in Asphalt Mixes Using X-ray Computed Tomography. Journal of Materials in Civil Engineering, v.14, n.2, p.122-129, 2002.

MICHAELIS. Dicionário Escolar: Língua Portuguesa. São Paulo: Melhoramentos. 2016.

MINISTÉRIO DOS TRANSPORTES. Departamento Nacional de Infraestrutura de Transportes. Manual de Pavimentação: Publicação IPR 719. Brasília: DNIT, 2006.

MINISTÉRIO DE MINAS E ENERGIA. Anuário Estatístico do Setor Metalúrgico. Brasília, 2016.

NIPPON SLAG ASSOCIATION. Production and Uses of Blast Furnace Slag in Japan. Tóquio, 2015.

NÓBREGA, L. M.. Caracterização mecânica de misturas asfálticas utilizando escória de ferroliga de manganês como agregado. Tese (Mestrado) - Universidade Federal da Bahia, Salvador, 2007

OLIVEIRA, R. W. H.. Caracterização da escória de ferro silício-manganês para aplicação como agregado em pavimentação ferroviária. Dissertação (Mestrado) Universidade Federal de Ouro Preto, 2013.

OLSEN, S. E.; TANGSTAD, M.. Silicomanganese production: process understanding. Trondheim: Norwegian University of Science and Technology, 2004

RODRIGUES, G. L. C.. Caracterização e avaliação da expansabilidade de escórias de aciaria LD não tratadas e tratadas. Dissertação (Mestrado) - Universidade Federal do Espírito Santo, 2007

TAKANO, C.; CAPOCCHI J. D. T.; NASCIMENTO, R. C.; MOURÃO, M. B.; SANTOS, D. M.; LENZ G.. A reciclagem de resíduos siderúrgicos sólidos. In: SEMINÁRIO NACIONAL SOBRE REUSO/RECICLAGEM DE RESÍDUOS SÓLIDOS INDUSTRIAIS. Anais. São Paulo, 2000.

TUTUMLUER, E.; PAN, T.. Aggregate Morphology Affecting Strength and Permanent Deformation Behavior of Unbound Aggregate Materials. Journal of Materials in Civil Engineering, v.20, n.9, 2008.

A CBPC - Companhia Brasileira de Produção Científica (CNPJ: 11.221.422/0001-03) detém os direitos materiais desta publicação. Os direitos referem-se à publicação do trabalho em qualquer parte do mundo, incluindo os direitos às renovações, expansões e disseminações da contribuição, bem como outros direitos subsidiários. Todos os trabalhos publicados eletronicamente poderão posteriormente ser publicados em coletâneas impressas sob coordenação da Sustenere Publishing, da Companhia Brasileira de Produção Científica e seus parceiros autorizados. Os (as) autores (as) preservam os direitos autorais, mas não têm permissão para a publicação da contribuição em outro meio, impresso ou digital, em português ou em tradução. 